\title{
Correction to: Embracing challenging complexity: exploring handwashing behavior from a combined socioecological and intersectional perspective in Sierra Leone
}

Hanna Luetke Lanfer ${ }^{*}$ and Doreen Reifegerste

Correction to: BMC Public Health (2021) 21:1857

https://doi.org/10.1186/s12889-021-11923-1

In this article [1] ref. 47 was missing and the first sentence of the Methods sections should be as shown below. The references and their in-text citation after the updated reference 47 have been renumbered. The original article has been updated.

\section{Methods}

Study design and setting

This research is part of a larger study to promote handwashing in a low-income environment [47].

Published online: 13 December 2021

\footnotetext{
References

1. Lanfer and Reifegerste Embracing challenging complexity. exploring handwashing behavior from a combined socioecological and intersectional perspective in Sierra Leone. BMC Public Health. 2021;21:1857. https://doi.org/10.1186/s12889-021-11923-1.

47. Luetke LH. Through a Lens of Scarcity: Health Communication in a LowIncome Context. Springer Fachmedien Wiesbaden; 2021.
} 